\title{
Gonçalo Tavares: o filho mais desenvolto de Álvaro de Campos? Convocação de textos
}

\author{
Madalena Var Pinto \\ (Universidade Federal do Rio de Janeiro)
}

\section{RESUMO}

Este texto foi escrito em forma de colagem. Em vez de escrever um texto sobre o autor, o que fiz foi convocar diferentes textos: de Gonçalo Tavares, de críticos e ensaístas portugueses, e combiná-los com comentários meus. Este foi o método que me pareceu apropriado para dar a ver a originalidade deste autor e o lugar particular que ocupa na literatura portuguesa. O título em forma de pergunta deixa que o resultado desta tentativa fique em suspenso, aberto ao julgamento de cada leitor.

PALAVRAS-CHAVE: Gonçalo Tavares, originalidade, colagem.

\begin{abstract}
This text was written as a collage. Instead of writing a text about the author, what I did was to call down different texts, from Gonçalo Tavares to ensaists and portuguese critics, besides my own comentaries. From my point of view, this was an appropriate method to show the originality of this author and his particular place among portuguese literature. The question in the title gives the reader the option to leave this text as an open experience.
\end{abstract}

KEYWORDS: Gonçalo Tavares, originality, collage. 
Este texto nasceu do efeito provocado pelos textos de Gonçalo Tavares. Que valor podem ter estes textos? Valor de perturbação, não de perpetuação.

O valor dos textos de Gonçalo Tavares está no questionamento sobre o que deve ter valor, em fazer do valor uma questão, uma procura, uma experimentação.

A experimentação é incompatível com a certeza.

Por onde começar? São tantos livros já escritos.

Poesia e prosa, poema em prosa, prosa poética, teatro, aforismos, investigações, romances. Convocar os textos. Fazer os textos falarem. Dizer os textos.

Dizer os textos do Gonçalo que dizem outros textos.

Tudo isto é tão novo, tenho medo de não conseguir. Não tenho medo de falhar, tenho medo de não conseguir dizer o que quero dizer para dizer o que o Gonçalo diz.

Estranha condição: portuguesa, no Brasil, a falar de literatura portuguesa, não só como objeto de estudo. A falar (no infinitivo) de dentro. Falar com os outros, através dos outros, pelos agenciamentos dos textos e das palavras.

\section{Comecemos com Eduardo Lourenço.}

Em 1966 o autor saudava a o aparecimento da nova literatura portuguesa. Ao contrário do neorrealismo que dominara a cena literária até então, a nova literatura caracterizava-se por uma neutralidade ética, "espécie de desconhecimento ou surdez que compunham a mitologia espiritual portuguesa" (LOURENÇO, 1994, p. 266).

Como exemplo da desconstrução dessa mitologia, Eduardo Lourenço citava o comportamento erótico tal como nessa literatura se manifestava, por ser o mais relevante, espetacular e tradicional tema. Mas, continua Lourenço, podia ter escolhido o tema da família, o da pátria ou de deus para mostrar como a habitual problemática ou a contestação a que costumava dar lugar, foi substituída, ou seja, como a tábua de valores dessa mitologia foi subvertida.

Tratava-se de uma espécie de revolução estética antes da revolução política de 74 .

O que parece ter acontecido é que a revolução democrática re-encaminhou a ficção portuguesa para a questão Portugal. Não que ela tenha sido abandonada, mas o caminho de experimentação que se vinha fazendo tinha posto a questão em segundo plano.

Passemos a Maria Alzira Seixo:

A ficção portuguesa contemporânea, após ter posto em causa a composição clássica do romance, como aconteceu um pouco em todas as literaturas ocidentais, devido às incidências da fenomenologia, do estruturalismo e da 
textualidade, [...] reabriu-se ao desejo da representação, aliando uma das mais neoclássicas concepções de romance que é possível observar no século XX a pequenas rupturas que lhe dão sentido novo ou lhe prosseguem fins determinados. (SEIXO, 1989, p. 53).

O romance português entrou na fase do "regresso à História enquanto matéria ficcional de eleição": José Saramago, Lobo Antunes, Lídia Jorge, Almeida Faria, Mário de Carvalho e muitos outros. Uma revisão da história, crítica, é claro, com ajustes de contas que tinham que se fazer, também é claro, e o romance português partiu para a investigação de Portugal. O romance português escreve e reescreve Portugal.

Literatura ensimesmada: lembraste o Camões? Citaste Pessoa? Não falaste da Sophia? E o Garrett, o Eça, o Camilo?

Anos mais tarde, comentava Eduardo Prado Coelho:

Há uma época, que não sei se acabou, mas que é aquilo que mais ressalta quando um estrangeiro se aproxima da literatura portuguesa de ficção: por um lado, Portugal viver muito preocupado com o seu passado e com essa liquidação do passado ou com a preocupação do passado, e, por outro lado, Portugal viver muito preocupado consigo mesmo enquanto país e isso ser uma espécie de tema obsessivo da literatura portuguesa. (COELHO, 1993, p. 47)

Que lugar tem Gonçalo Tavares na tradição da literatura portuguesa?

Portugal não existe na literatura de Gonçalo Tavares. Nem Portugal nem portugueses. Os nomes dos personagens - Mylia, Ernest, Hanna, Theodor, Joseph Walser, Klaus Klump, Margha, Catharina, Klober, Fluzst, entre outros, contribuem para impedir a identificação com a realidade portuguesa, confirmando a distância desta literatura de questões como identidade. Este aspecto, por si só, desperta a curiosidade sobre este escritor em meio a uma literatura onde é comum pensar a subjetividade relacionada com problemas da identidade.

"Pessoalmente não quero conhecer e investigar o Homem Português, quero sim perceber e investigar o homem, no geral, e seus comportamentos" (TAVARES, Editora Caminho Online www.editorial-caminho.pt, 2005 ).

Isto não significa que o escritor não dê importância à cultura a que pertence e à língua em que essa cultura se expressa:

Eu escrevo em Língua portuguesa e esse é um ponto de partida fundamental. Mas a literatura é um assunto de homem, não de pátrias. Os grandes temas humanos atravessam os vários homens dos vários países. Podemos exprimir a dor que sentimos numa Língua, mas a dor, ela própria não tem gostos ou restrições lingüísticas. (TAVARES, Editora Caminho Online www.editorialcaminho.pt, 2005 ). 
Nos Lirros Pretos Gonçalo Tavares investiga comportamentos humanos. Esta investigação não se apoia nas determinações psicológicas dos personagens. Trata-se de investigar comportamentos humanos, no mundo de hoje, num lugar não identificado geograficamente, sem particularidades "culturais". Como diz o autor: "[O mundo] não é um lugar estrangeiro, porque não há nenhum lugar estrangeiro ao medo, à agressividade, à loucura, à ligação entre pais e filhos." (M. Tavares, Entrevista concedida ao Círculo dos Leitores online: www.circuloleitores.pt/cl/ , 2004).

Não há esconderijo para a existência. (TAVARES, 2006b. p. 97).

\section{Estratégia narrativa:}

descrição desassombrada, capítulos curtos, impedir a empatia, mudar o ritmo, não deixar fluir.

Enredos mínimos, personagens impessoais.

Não é só isso que é original neste autor. É também a dicção impessoal, a inexistência de um narrador que oriente o texto: mostrar, apresentar, não adjetivar, não julgar.

Em Portugal hoje: o medo de existir, escreve José Gil:

[Em Portugal] a arte é uma questão privada. Não entra na vida. Não modifica as existências individuais [...] alguém já ouviu dizer que a literatura de Saramago influenciou a sua vida? Ou a maneira de pensar de Lídia Jorge modificou a visão que os portugueses (leitores) têm da história e dos homens? [...] A literatura não entrou no espaço público, porque não há espaço literário que exista por si. [...]. A sua característica primeira é a de constituir uma exterioridade, um "fora" para os sujeitos (individuais ou colectivos) que neles penetram. [...] Aí o livro ou obra de arte perde a sua marca de origem, a "função autor" dissolve-se, o objecto ganha um anonimato que faz com que já não pertença a um, mas simultaneamente a todos e a ninguém. Quando é devolvido ao seu autor é irreconhecível, transformou-se consideravelmente. Ganhou poderes insuspeitados, forças desconhecidas atravessam-na. [...] Vê-se que o espaço público falta cruelmente em Portugal. Quando há diálogo, nunca ou raramente ultrapassa as 'opiniões' dos dois sujeitos personalizados (cara, nome, estatuto social) que se criticam mutuamente através de suas crônicas nos jornais respectivos (ou no mesmo jornal). O 'debate' é necessariamente 'fulanizado', o que significa que a personalidade social dos interlocutores entra como uma mais valia de sentido e de verdade no seu discurso. (GIL, 2004, p. 27-30). 
Senti sempre a matemática como uma presença

Física; em relação a ela vejo-me

Como alguém que não conseguiu

Esquecer o pulso porque vestiu uma camisa demasiado

Apertada nas mangas

Perdoem-me a imagem: como

Num bar de putas onde se vai beber uma cerveja

E provocar com a nossa indiferença o desejo

Interesseiro das mulheres, a matemática é isto: um

Mundo onde entro para me sentir excluído;

Para perceber, no fundo, que a linguagem, em relação

Aos números e seus cálculos, é um sistema,

Ao mesmo tempo, milionário e pedinte. Escrever

Não é mais inteligente que resolver uma equação;

Porque optei por escrever? Não sei. Ou talvez saiba;

Entre a possibilidade de acertar muito, existente

Na matemática, e a possibilidade de errar muito,

Que existe na escrita (errar de errância, de caminhar

Mais ou menos sem meta) optei instintivamente

Pela segunda. Escrevo porque perdi o mapa.

O mapa (TAVARES, 2001a, p. 163)

Provocar o estranhamento constitui-se no modo de intervenção deste escritor: "Alguém ficar intrigado é, julgo eu, um ganho. Há uma satisfação diferente quando se entende tudo por completo ou quando se entende em parte, e a parte que falta provoca mudanças, curiosidade, etc" (M. Tavares, Entrevista concedida ao Círculo dos Leitores online: www.circuloleitores.pt/cl/ , 2004). Seria esta a forma de exercer uma política através da escrita: uma escrita é política porque experimenta, e nessa experimentação questiona formas estabilizadas obrigando à invenção de novas formas de existência e pensamento.

Toda a literatura é assunto de letras paradas fazerem ou não as coisas do mundo moverem-se. A literatura poderá ser um esplêndido sistema, mas é feito de letras, um alfabeto estático. Campo em estado de invenção, preparado para as flores e para as árvores do descanso e do alimento, o alfabeto, eis. Mas parado.

Mas agir é diferente.

[...] Ninguém escreve actos, nem o I, nem o II, muito menos o último. Escrever acções é talvez uma das grandes vontades de qualquer escritor, mas escrever acções é acontecimento que não ocorre desde que os homens perceberam que entre as palavras e as coisas há um incêndio; e tanto as palavras como as coisas são feitas de material que cede a este fogo a sua forma. Nem as palavras nem as coisas sobrevivem ao incêndio que é feito de temperatura exacta. Se quiseres ir para o outro lado perderás todas as tuas qualidades, eis a conversa de café entre a literatura e as acções do mundo. Nem se escrevem actos, nem os actos deixam letras atrás de si. São dois mundos: um, dois. 
[...] Toda a escrita, pelo menos a decente, ou seja: a magnífica, toda a escrita instala, é certo, uma promessa de movimento, de acção.

[...] Há versos de uma beleza tão rápida que fazem com que o futuro seja imediatamente à frente do sítio onde agora agimos. Se esticarmos a mão podemos tocar o futuro, é isto também a literatura (TAVARES, 2003a, p. 61-62).

Uma promessa de movimento, de ação. Se esticarmos a mão. A mão que sai de um corpo.

Como são os corpos da literatura portuguesa? Não o corpus, os corpos.

A decadência dos povos pode ser não aceitar a decadência dos corpos, repara.

Os textos de Gonçalo Tavares têm corpo

Um corpo não inquisidor nem inquisitorial

Um corpo que dança.

Uma dança feita de movimentos incondicionados, não aleatórios.

Dançar e obrigar os outros ao susto, é dizer: qualquer momento é possibilidade de voltar ao início, descer à Cave, à Biologia, à CARNE.

(TAVARES, 2001, p. 109).

EVITAR a camuflagem: o corpo

Profundo é o corpo entre as fezes

e a beleza. (TAVARES, 2001, p. 20).

Aceitar a FRATURA, a

NEVROSE, o psicopata, a dor, aceitar tudo isso como se fosse a idéia NOVA mostrada por quem dança. (TAVARES, 2001, p. 14).

O erro do Ocidente: separar o "conhece-te a ti mesmo" do "cuidado de si”. Não integrar o corpo na busca da verdade. Robotizar o corpo, embelezar o corpo, mas ignorar a verdade que o corpo diz.

Dançar é ganhar confiança no corpo (TAVARES, 2001, p.17)

Acredito em tudo o que aprendi antes dos seis anos de idade (TAVARES, 2003a, p. 41) 


\section{Verdadeiro e falso}

Substituir a expressão:

- Isto é verdadeiro.

Pela expressão:

- Isto é a verdade desta coisa.

Não é a tua teoria que é verdadeira; a tua teoria detectou a verdade de um fenômeno (pelo menos acreditas nisso). Nada é verdadeiro ou falso. Tudo existe e umas vezes simula e mente, outras vezes não.

- Isto é verdadeiro e falso. E a parte que é verdadeira disto é esta.

(E assim tens na mão a tua teoria científica.)

(TAVARES, 2006a, p. 89).

De volta ao corpo, à aprendizagem com corpo, sem eliminar nada.

O que é uma bailarina que não tenha "vergonha" das Fezes? [...] Em vez de abstrair, escondendo as fezes, ilustrando um coração sem lixo, ela deve ser tendões e urina e vagina e ânus e pênis. [...] Em vez de divina, ela deve ser 'uma síntese de aurículas e Lixo'. A transformação dos alimentos em fezes, a circulação do sangue, a morte das células, eis o que ela não deve esconder, mas expor: a dança seria criminosa se apenas mostrasse uma pele e abstrações. Mas a dança de Gonçalo Tavares é a mostração do interior do corpo [...] no exterior. Dançar: mostrar fora o que acontece dentro. Sem anjos nem deuses. (EIRAS, 2006, p. 23).

Nenhum mistério: apenas certas pessoas não gostam de ser indecentes. $O$ coração não é só uma víscera tenra. Há um sistema moral algures na parte mole do corpo. [...]

Os tribunais privados, íntimos, impõem mais respeito do que a montanha.

Um homem: Klaus Klump. (TAVARES, 2003b, p. 5556)

Supor que há elementos do corpo que não sofrem nem se exaltam, que apenas assistem, parece um equívoco.

Um homem: Klaus Klump. (TAVARES, 2003b, p. 100)

Há exercícios para treinar a verdade, como por exemplo, ter medo. Ou então ter fome. Depois restam exercícios para treinar a mentira: todos os grupos são isto, e todos os negócios.

Estar apaixonado é uma outra forma de exercitar a verdade.

Um homem: Klaus Klump (TAVARES, 2003, p. 132). 
Livros Pretos. A negritude destes livros vem de seus horizontes sem saída, onde os personagens circulam numa atmosfera claustrofóbica, que lembra os filmes de Lars Von Triers ou as peças de Beckett.

Da tensão entre racionalidade e imponderável. De um lado a loucura, a fragilidade, a doença. De outro a técnica, a vontade de dominar, de eliminar os mistérios da existência. De encontrar uma fórmula que faça o mundo tornar-se previsível.

O médico sou eu, não te esqueças. Eu é que decido quando é que as pessoas estão saudáveis e doentes. (TAVARES, 2005, p. 48)

Mostrar o mal. Sem transcendência. Está ali, vem cá, vou mostrar-te. O mal é aquilo de que somos capazes quando... Lançar o desafio da escolha ética.

O que está do outro lado do mal? Esse corpo que não aguenta mais. Não aguenta, mas apesar de tudo ainda respira.

Não temos outro corpo. Não temos outro mundo.

Voltar ao corpo. Só esse corpo sujo e belo, frágil e monstruoso pode ainda inventar formas de viver. As inesperadas.

A guerra que muda a paisagem. Os homens olham de lado, as mulheres tremem, as máquinas assumem a linha da frente. Encontrar na matemática a fórmula para decidir o futuro.

Medicina e guerra: duas formas de utilizar a mão direita.

Aprender a rezar na Era da técnica. (TAVARES, 2007, p. 104)

O mundo por vezes amputa um braço dos homens que estão do lado de fora da janela. Vê o mundo, o mundo tem uma lâmina. (TAVARES, 2003b, p, 16). 


\section{REFERÊNCIAS BIBLIOGRÁFICAS}

COELHO, Eduardo Prado. "Tudo aquilo em que acredito". Em: Ler, n.24, outono Lisboa: Círculo dos leitores, 1993, p. 44-57.

EIRAS, Pedro. A moral do vento. Ensaio sobre o corpo em Gonçalo M. Tavares. Lisboa: Caminho, 2006.

GIL, José. Portugal hoje: o medo de existir. Lisboa: Relógio D’Água, 2004.

LOURENÇO, Eduardo. O canto do signo. Lisboa: Presença, 1994.

SEIXO, Maria Alzira. Lugares da fição em José Saramago. Lisboa: INCM, 1999.

TAVARES, Gonçalo. 1. Lisboa: Relógio D'Água, 2001a. . Lirro da Dança. Lisboa: Assírio e Alvim, 2001b. A colher de Samuel Beckett. Porto: Caminho das Letras, 2003a. . Um homem: Klaus Klump. Lisboa: Caminho: 2003b. - Jerusalém, 5a . Ed. Lisboa: Caminho, 2005. - Breves notas sobre a ciência. Lisboa: Relógio D’ Água, 2006a. - A máquina de Joseph Walser, $2^{\mathrm{a}}$. Ed. Lisboa: Caminho, 2006b. Aprender a rezar na era da técnica. Lisboa: Caminho, 2007. . Entrevista concedida à revista Círculo dos Leitores. Rerista online. Disponível em: www.circuloleitores.pt/cl/ 2004.

. Entrevista concedida à Editora Caminho online. Disponível em: www.editorialcaminho.pt 2005. 